OPEN ACCESS

Edited by:

Xavier Noel,

Free University of Brussels,

Belgium

Reviewed by:

Diane Carol Gooding,

University of Wisconsin-Madison,

United States

Henry W. Chase,

University of Pittsburgh,

United States

*Correspondence:

Emma Barkus

ebarkus@uow.edu.au

Specialty section:

This article was submitted to

Psychopathology,

a section of the journal

Frontiers in Psychiatry

Received: 12 November 2018

Accepted: 25 March 2019

Published: 24 April 2019

Citation:

Barkus E and Badcock JC

(2019) A Transdiagnostic

Perspective on Social Anhedonia.

Front. Psychiatry 10:216.

doi: 10.3389/fpsyt.2019.00216

\section{A Transdiagnostic Perspective on Social Anhedonia}

\author{
Emma Barkus $^{1 *}$ and Johanna C. Badcock ${ }^{2}$ \\ ${ }^{1}$ Cognitive Basis of Atypical Behaviour Initiative (CBABi), School of Psychology, University of Wollongong, Wollongong, \\ NSW, Australia, ${ }^{2}$ Centre for Clinical Research in Neuropsychiatry (CCRN), Division of Psychiatry, Faculty of Health \\ and Medical Sciences, The University of Western Australia, Perth, WA, Australia
}

Humans are highly social beings, yet people with social anhedonia experience reduced interest in or reward from social situations. Social anhedonia is a key facet of schizotypal personality, an important symptom of schizophrenia, and increasingly recognized as an important feature in a range of other psychological disorders. However, to date, there has been little examination of the similarities and differences in social anhedonia across diagnostic borders. Here, our goal was to conduct a selective review of social anhedonia in different psychological and life course contexts, including the psychosis continuum, depressive disorder, posttraumatic stress disorder, eating disorders, and autism spectrum disorders, along with developmental and neurobiological factors. Current evidence suggests that the nature and expression of social anhedonia vary across psychological disorders with some groups showing deficient learning about, enjoyment from, and anticipation of the pleasurable aspects of social interactions, while for others, some of these components appear to remain intact. However, study designs and methodologies are diverse, the roles of developmental and neurobiological factors are not routinely considered, and direct comparisons between diagnostic groups are rare-which prevents a more nuanced understanding of the underlying mechanisms involved. Future studies, parsing the wanting, liking, and learning components of social reward, will help to fill gaps in the current knowledge base. Consistent across disorders is diminished pleasure from social situations, subsequent withdrawal, and poorer social functioning in those who express social anhedonia. Nonetheless, feelings of loneliness often remain, which suggests the need for social connection is not entirely absent. Adolescence is a particularly important period of social and neural development and may provide a valuable window on the developmental origins of social anhedonia. Adaptive social functioning is key to recovery from mental health disorders; therefore, understanding the intricacies of social anhedonia will help to inform treatment and prevention strategies for a range of diagnostic categories.

Keywords: schizotypy, schizophrenia, eating disorders, autism spectrum disorders, posttraumatic stress disorder, depression

\section{INTRODUCTION}

The need to belong is fundamental to human behavior, shaping our motivation for and maintenance of social relationships $(1,2)$. Understanding the nature of this need is central to appreciating how social connection buffers mental well-being (3). Instances where individuals exhibit a reduced interest in and/ or pleasure from social engagement therefore present a conundrum. Accordingly, social anhedonia, a 
trait-like disinterest in and lack of reward from social engagement (4-7), is attracting a resurgence of interest (8). While social anhedonia is associated with social withdrawal, it is distinct from social anxiety, where withdrawal from social situations is driven by a fear of negative evaluation, rather than lack of reward from social situations. That is, social anhedonia stems from diminished positive affect from social contact, rather than heightened negative affect (9). Similarly, social anhedonia is not simply an extreme form of introversion, which is characterized by low positive emotion and a preference for solitude (10). Rather, it seems comparable to (low) social closeness captured in the personality literature (11). In short, social anhedonia is not merely a reflection of diminished social interest, but at its core entails a reduced positive appraisal of all aspects of interpersonal relationships. Although social anhedonia is a key element of schizotypy and schizophrenia $(6,12$, $13)$, it is increasingly recognized transdiagnostically (14), spurring the development of a wide range of subjective (e.g., Table 1) and objective tools for its assessment.

The scales used in the social anhedonia literature move from the focused RSAS to the measures of social reward and the experience of pleasure in general, with a lesser or greater emphasis on the social context. These scales therefore provide different information about social anhedonia directly or the experiences that underpin it, such as social reward. Criticisms with the content of early self-report scales (22) have driven more recent efforts to uncover the multidimensional nature of social anhedonia, in part to reflect a more nuanced understanding of the cognitive processes that could be driving social anhedonia. While our understanding of anhedonia has been slow to evolve, experimental and preclinical work has provided increments in knowledge concerning hedonic experiences. Current evidence suggests that, cognitively, pleasurable or rewarding experiences, in general, comprise a "looking forward to" anticipatory component, which is cognitively driven (i.e., "wanting") $(23,24)$, and an "in-the-moment enjoyment" (i.e., "liking") component $(25,26)$. A third component, "learning," ensures that individuals pair their social experiences with positive pleasurable emotions and consequently seek out similar future experiences (27). The interest in the pleasure cycle has led some authors to increasingly suggest that the broader concept of anhedonia should distinguish between motivation or seeking behaviors and in-the-moment pleasure of an experience (28). Self-report measures such as the TEPS and the ACIPS have attempted to parse these anticipatory and consummatory components of pleasure into more human social domains, with varying success. The ACIPS, although in early days of use, may prove to be an additional general measure of social anhedonia. It is recognized that pleasure, reward, learning, anhedonia, and social anhedonia are all distinct concepts. However, accumulating evidence from preclinical, translational, basic, and applied human research points to these concepts being related to one another. Processes related to the experience of pleasure and reward likely provide the mechanisms underpinning the behavioral expression of social anhedonia. Consequently, there is a need to understand specific types of anhedonia (29), which drives the encompassing nature of the current review. Understanding which components of cognitive processing are altered in people with social anhedonia-regardless of diagnostic category-could assist in improving social functioning (30, 31) and therapeutic outcomes (32). Yet, despite the potential significance of social anhedonia in both clinical and nonclinical groups, a synthesis of current evidence is lacking. Consequently, here we provide a selective review of the literature, highlighting similarities and differences in social anhedonia across a variety of presentations. Studies have been included on the basis that they have a focus on social anhedonia or anticipatory and consummatory components of reward and hedonic responses.

\section{PSYCHOSIS CONTINUUM}

By far, the largest body of work concerning social anhedonia relates to the psychosis continuum. Though subject to much debate, the continuum model posits that psychotic disorders comprise an extended phenotype of risk, with diagnosable disorders such as schizophrenia at one extreme end and nonclinical high, average, and low levels of schizotypy (associated with decreasing levels of psychosis risk) at the other (33). Underlying schizotypy is a multidimensional structure of personality traits broadly similar

TABLE 1 | Common self-report and interview measures for social anhedonia (SA) and related constructs.

\begin{tabular}{|c|c|c|}
\hline References & Name of measure & Description \\
\hline Eckblad et al. ${ }^{a}$ & Revised SA Scale (RSAS) & $\begin{array}{l}\text { Self-report-trait. Captures associability, lack of social enjoyment, } \\
\text { indifference to others. }\end{array}$ \\
\hline Foulkes et al. (15) & Social Reward Questionnaire & Self-report-captures individual differences in the value of social rewards. \\
\hline Fawcett et al. (16) & Fawcett-Clark Pleasure Capacity Scale (FCPS) & $\begin{array}{l}\text { Self-report-people's subjective responses to normally pleasurable } \\
\text { situations. }\end{array}$ \\
\hline Gard et al. (17) & Temporal Experiences of Pleasure Scale (TEPS) & Self-report-trait. Anticipatory and consummatory pleasure experiences. \\
\hline Gooding and Pflum (18) & $\begin{array}{l}\text { Anticipatory and Consummatory Interpersonal } \\
\text { Pleasure Scale (ACIPS) }\end{array}$ & $\begin{array}{l}\text { Self-report-trait. Forward looking and immediate enjoyment of social } \\
\text { interactions. }\end{array}$ \\
\hline Gooding et al. (19) & $\begin{array}{l}\text { Anticipatory and Consummatory Interpersonal } \\
\text { Pleasure Scale (ACIPS-A) }\end{array}$ & As above but for adolescents. \\
\hline Kirkpatrick et al. (20) & Brief Negative Symptom Scale (BNSS) & $\begin{array}{l}\text { Interview-symptom. Subscales anhedonia, intensity of pleasure and } \\
\text { frequency of pleasure correlate with other SA scales. }\end{array}$ \\
\hline Snaith et al. (21) & Snaith-Hamilton Pleasure Scale (SHAPS) & Self-report-hedonic capacity. \\
\hline
\end{tabular}

aEckblad ML, Chapman LJ, Chapman JP, Mishlove M. (1982). The revised social anhedonia scales. (Available from LJ. Chapman, Department of Psychology, 1202 West Johnson Street, University of Wisconsin, Madison, WI 53706.) 
to the symptom presentation observed in psychotic disorders, lending further support to structural continuity between clinical and nonclinical experiences [see also Ref. (34)]. In the psychosis continuum literature, social anhedonia is a feature of the negative dimension and is thought to be trait-like, enduring and stable over the illness course irrespective of symptom fluctuation $(5,35)$.

\section{Nonclinical Populations and Social Anhedonia}

First, we will consider studies involving nonclinical individuals expressing social anhedonia. People drawn from the general healthy community with high levels of social anhedonia report fewer personal relationships $(30,36)$, are less likely to be in intimate relationships (37), prefer to be alone (30), are less committed to, and experience fewer positive feelings toward, their partner when in a relationship (31). Llerena et al. (38) reported that self-reported social anhedonia was associated with less willingness to engage in social interactions, reduced social skills, and less positive responses to an experimental social interaction. Nonetheless, high levels of social anhedonia-at least in healthy young adults-are associated with high levels of loneliness (39). This suggests that while the enjoyment of, or wanting for, social interaction in people with social anhedonia is low, or subjectively dampened, it is not entirely absent, since reduction below the desired level still triggers a sense of absence and the pain of loneliness.

Neurocognitive deficits are present in some healthy individuals who express social anhedonia, although these cognitive deficits do not appear to be related to general (psychological, social, or occupational) functioning (40). Cohen et al. (40) reported that those scoring highly on social anhedonia had poorer performance on a standard assessment of attentional vigilance; similarly, Tully et al. (41) found that attentional control mediated the relationship between social anhedonia and social functioning. Although tentative, these two papers suggest that the capacity to attend to, and ultimately learn from, important aspects of one's environment may be a key issue in social anhedonia. The results from Pflum and Gooding (42) support this idea, since participants scoring highly on social anhedonia were less able to use social context and therefore had poorer performance when it was relevant in tasks assessing social cognition. In addition, improving working memory capacity in those with social anhedonia from the general population has been reported to improve the anticipatory component of reward and lead to upregulation of brain regions related to monitoring and reward $(43,44)$. Within the general population, social anhedonia is associated with negative social outcomes, indicating poor engagement, maintenance, and affiliation for interpersonal relationships (45), and is predictive of the risk of developing schizophrenia in the future $(13,45)$.

\section{Psychosis Clinical Samples}

Moving into clinical samples, a reciprocal relationship appears to exist between poor premorbid social adjustment and increased levels of social anhedonia in help-seeking youth at clinical high risk for psychosis (46). Potentially, this could initiate a downward spiral of loss of social skills, decreased motivation to engage, and reduced pleasure from social situations. Using an experimental social interaction paradigm, McCarthy et al. (47) reported that in patients with schizophrenia, higher ratings on social anhedonia were associated with reduced feelings of interpersonal closeness and less willingness to interact, with subjective responses during interactions with the experimental partner being related to social functioning in general. Conversely, in treatment-resistant patients with schizophrenia, lower levels of anhedonia-asociality predicted a longer time living in the community between admissions (48). Patients with schizophrenia and schizoaffective disorder who had high levels of social anhedonia had higher levels of symptomatology and lower levels of self-esteem, selfefficacy, subjective recovery, social support, and poorer quality of life compared to patients with intact hedonic responses and an intermediary group (49). Collectively, these studies suggest that increased social anhedonia and related constructs diminish social functioning and willingness to engage in social interactions in those at risk for or diagnosed with psychosis. Given the similar findings in nonclinical samples, social anhedonia, rather than positive psychotic symptoms, may be responsible for decreased social engagement across the psychosis continuum.

\section{Cognitive Underpinnings of Social Anhedonia Along the Psychosis Continuum}

There have been fewer formalized experimental paradigm studies tapping the cognitive underpinnings of social anhedonia. People from the general population who score highly on social anhedonia report difficulties in controlling the effects of emotional information on behavior $(50,51)$, less positive affect in response to positive pictures, videos, and words (52-54), and rated sad and neutral faces more negatively (55). In patients with schizophrenia, interest has developed in "basic" symptoms; these are subtle changes from "normal" in subjective experiences of emotions, the self, and perceptions of the world (56). The basic symptoms that capture a need to consciously reflect on usual activities, reduced social motivation and emotional meaning, and lower stress thresholds were all associated with higher social anhedonia in patients with schizophrenia (57). Together, these studies suggest that in those from the general community and patients with schizophrenia, social anhedonia is associated with alterations in the subjective experience of, and objective responding to, emotionally loaded social cues.

In other clinical disorders, there has been an increasing emphasis on parcelling out the learning, wanting, and consummatory components of pleasure. Given the evidence of dysregulation in dopamine in those with psychosis, there has been much characterization of the motivational and rewardrelated problems reported in patients with schizophrenia (58). For example, in two studies (one using experience sampling methodology and the second employing cross-sectional questionnaires), Gard et al. (59) reported that patients with schizophrenia had intact in-the-moment (i.e., consummatory) positive emotions in response to events; however, they displayed deficits in positively anticipating future events when compared to healthy controls. However, it is only relatively recently that 
separating consummatory and anticipatory reward has been extended to social anhedonia across the psychosis continuum. Intact positive emotional responses to external stimuli, in those with social anhedonia, have not been consistently reported (52).

When examining the learning component, during reward paradigms, people expressing higher levels of social anhedonia changed their responding style less in reaction to social, but not monetary, rewards $(60,61)$, demonstrating less favorable responses to social cues than would be expected. Therefore, it appears that diminished experience of reward in social anhedonia along the psychosis continuum may be specific to social stimuli (61). Patients with schizophrenia who have social anhedonia are less able to modulate positive emotions (63), anticipate future pleasure (59), or use previous positive experiences to motivate future behaviors (63). Again, however, anhedonia in psychotic disorders is associated with high levels of loneliness (64), suggesting that the enjoyment of social interactions is diminished in people with psychosis, but sensitivity to pain from (inadequate) social connections remains. Potentially, the feeling of loneliness could derive from the reduced hedonic response to social interactions, or this could be a precursor to the tipping point between transient and chronic loneliness. Given that a significant component of social connections extends from positive responses (65), more specifically positive connection to people, reduced pleasure from social engagement could impair an individual's capacity to gain meaningful connections. In addition, given that social withdrawal occurs in social anhedonia, it provides a potential blockage to reinstating social connections and alleviating loneliness (66). Impaired learning will then make it hard to recouple social approach behaviors and motivation with positive emotional experiences (67). Collectively, perhaps, these studies point to a breakdown in the learning component of reward, which may underpin diminished expression of anticipatory positive emotions in relation to positive future events. In turn, a deficit in anticipatory reward could impair social approach behaviors and lead to less engagement in social activities and ultimately diminish social functioning.

\section{DEPRESSIVE DISORDERS}

Anhedonia is a core component of depressive disorders. However, there is limited research on social anhedonia specifically. Emerging literature suggests that anhedonia may be trait-like and predictive of both risk of onset and relapse for major depression (68). Yet, in depression, some argue that social anhedonia is coupled to clinical state and improves with recovery (5). One study involving clinically active patients with depression reported that those with depression had higher levels of social anhedonia compared to individuals with schizophrenia (69). Social anhedonia may be present at clinically significant levels in approximately a third of patients with depression (70). As a continuous measure, social anhedonia is associated with depressive symptom severity (7072 ) and poor treatment response $(68,73)$. Deficits in the reward system of those with depression have been previously considered. For instance, reduced motivation for reward is thought to be driven by deficits in the anticipation of rewards, while enjoyment of in-the-moment consummatory reward remains intact (74). However, studies concerning social anhedonia in those with depression tend to capture behavioral correlates and not the cognitive underpinnings.

Evidence that social anhedonia and depressive symptoms are related in the general population could contribute evidence toward social anhedonia being viewed as a trait-like vulnerability rather than coupled with clinical state. Anticipation of a less positive response to social situations is reported in females, from the general population, with high levels of depressive symptoms compared to those with low depressive symptoms (75). Certainly, cognitive vulnerabilities for depression such as increased self-focus tend to lead to difficulties in interpersonal relationships (76). Focus on one's own internal states reduces engagement with the social environment, blunts in-the-moment emotional responses, and diminishes social skills. For instance, reduced emotional facial expression and less smiling (77) are reported in depression and may exacerbate social anhedonia $(53,78)$. These psychological characteristics could compromise cognitive capacities, reducing the cognitive resources available to engage in social situations actively. In a working memory training program for those with psychometrically defined depression, although ratings of depression decreased and hedonic experiences increased, social anhedonia remained the same pre- and posttraining (79). This study suggests, that while improvements can be gained in the anticipation of future events through cognitive remediation, it might be more difficult to change patterns of behavioral responses in general. However, the possibility that working memory training could improve anticipatory reward in those with anhedonia, in general, suggests that cognitive capacities could be a target to improve positive emotions toward social engagement and may in the longer term lead to changes in social behaviors. For instance, the absence of perceived positive social cues (through cognitive biases related to anhedonia) during interactions could reduce the rewarding properties of social interactions. For example, in patients with schizophrenia, higher ratings of social anhedonia reportedly correlate with self-depreciation, guilty ideas of reference, pathological guilt, early wakening, suicidality, and observed depression (80). Other studies suggest that social anhedonia is temporally linked to episodes of clinical depression (81). In conclusion, depression and social anhedonia may co-occur in subclinical and all clinical disorders where depression is present. Further longitudinal research is needed to investigate whether social anhedonia is a stable risk temperament for depressive disorders or present only during an active depressive episode, regardless of primary diagnosis.

\section{EATING DISORDERS}

Eating disorders, such as anorexia nervosa (AN) and bulimia nervosa $(\mathrm{BN})$, are characterized by disturbances in behavioral and neurobiological responses to food rewards (82). There are a number of reviews that consider the role of reward, in general, in eating disorders (83-86). It is beyond the focus of the current review to reiterate the work that others have already provided 
focused reviews on. However, given the focus on reward as a core concern in the nature of eating disorders, hedonic responses have consistently been separated into anticipatory and consummatory components. Anhedonia, in general, is also a focus of interest in eating disorders, though developing a single unifying framework is proving a challenge (87). For example, some argue that eating disorder patients show a diminished sense of pleasure from food; others report that hedonic impact is intact but the desire for food is impaired (88-90). Some forms of eating disorders may be associated with normal levels of wanting but low levels of liking food, while BN may be associated with an excessive wanting of food that is not followed by a typical sense of pleasure (82). Such complexity illustrates the heterogeneity in eating disorders; however, it is immediately evident that reward processes are key to clinical symptoms.

Beyond reward difficulties in relation to food, current models also recognize the importance of social and emotional difficulties in the development, maintenance, and recovery from eating disorders $(91,92)$. These include increased sensitivity to social rejection and alexithymia, along with poor social cognition and decreased sensitivity to social rewards (93-95). Within this complex profile, some studies have examined social anhedonia in eating disorders using self-report measures. The results showed that people with $\mathrm{AN}$ and $\mathrm{BN}$ have significantly higher scores on the Revised Social Anhedonia Scale than those without eating disorders (96-98), while those who had recovered from AN had intermediate levels of social anhedonia. Levels of social anhedonia do not differ between women with $\mathrm{AN}$ and BN (99), are highly correlated with illness chronicity, and significantly predict problems with social and occupational functioning (97). Evidence from behavioral studies suggests women with AN avoid looking at the faces and eyes of others and find them less rewarding compared to non-eating disorder controls (100), while at the neural level, areas of hypo- and hyperactivation have been identified in response to positive and negative social exchanges, respectively $(101,102)$. Together, these data suggest that reward dysfunction in people with eating disorders is not specific to food-related stimuli or body image but encompasses abnormal motivational drive and pleasure from social interactions. Whether this is a cause or a consequence of eating disorders is still unclear; however, given its potential impact on recovery, social anhedonia is now serving as a specific treatment target for psychological interventions (103). Social anhedonia has been reported to reduce following an intervention comprising cognitive remediation and emotion skills training in adults with anorexia $(103,104)$.

The presence of social anhedonia in eating disorders suggests that there may be overlapping mechanisms for social reward mirroring those found in other groups, such as autism spectrum disorders (ASD; see the section Autism Spectrum Conditions) and along the psychosis continuum. Indeed, elevated rates of both ASD traits and psychotic symptoms are present in patients with eating disorders (105-107). The presence of ASD traits in those with anorexia has been reported to be positively related to social anhedonia (108). Delineating the differences between diagnostic categories, eating disorder subtypes, and reward components (liking, wanting, and learning) is an important direction for future research. For example, alexithymia scores were found to be strongly associated with social anhedonia in eating disorders; thus, in contrast to ASD (109), impaired enjoyment of social interactions in eating disorders may be related to difficulties identifying and expressing feelings (96).

\section{POSTTRAUMATIC STRESS DISORDER}

Like depressive disorders, anhedonia is also a central symptom of PTSD $(110,111)$. Greater anhedonia in PTSD has been linked to an increased risk of psychotic disorder $(112,113)$ and poor social functioning (114). While early research focused on fearrelated processes, a growing recognition of alterations in reward processing $(115,116)$ led to a reconceptualization of PTSD as an imbalance between approach (reward-related) and avoidance (fear-related) systems (117-119). Consequently, as with eating disorders, PTSD research has been focused on characterizing the anticipatory and consummatory behaviors related to social anhedonia. More recently, a systematic review of self-report, behavioral, and neurobiological measures yielded a complex and mixed pattern of results for reward functioning in people with PTSD. Variation in results may reflect heterogeneity of the causes, symptoms (120), and underlying reward mechanisms (121) of posttraumatic stress. Overall, however, a tendency to both reduced consummatory and motivational reward was noted, especially in females with PTSD and in response to positive social stimuli compared to nonsocial stimuli, suggestive of social anhedonia (118). For example, women with PTSD report less positive affect in response to positive interpersonal (social) memories, along with lowered neural activation in ventral striatal reward networks responsive to rewarding and socially salient stimuli (122). Reduced motivation to approach socially rewarding stimuli may be particularly evident in those with PTSD when greater effort is needed to gain reward (118), suggesting reduced sensitivity in the cognitive underpinning for "wanting" social connections.

In addition to an inability to feel pleasure, people with PTSD, especially related to prolonged childhood abuse, often have a different kind of hedonic problem. Specifically, traumatized individuals report an aberrant hedonic tagging such that they experience negative emotional responses to usually positive events. This specific form of anhedonia, termed negative affective interference, reflects disruption in reward learning in the context of previously adverse social experiences (123), for example, associating positive social contact (e.g., touch) with fear and sexual abuse. Self-report data indicate that negative affective interference is positively correlated with depression and PTSD symptoms (124). However, despite the well-recognized link between early childhood trauma and depression (125), schizotypy (126), and schizophrenia (127), the role of negative affective interference has received scant attention transdiagnostically and has not been considered in relation to social anhedonia specifically.

\section{AUTISM SPECTRUM CONDITIONS}

Autism spectrum disorders (ASD) and schizophrenia spectrum disorders are neurodevelopmental disorders with overlapping feat ures of social dysfunction (128), reflecting both shared 
and distinct component processes (129, 130). Early clinical descriptions of autism (131) noted a clear lack of interest in and pleasure from social stimuli, which are also associated with autistic traits in the general population, suggesting that social anhedonia may be a stable part of the broader autism phenotype (132).

Self-report measures of negative schizotypy have been used to index anhedonia in many studies concerning those with autism (133-138). For example, Rawlings and Locarnini (133) showed that scores on the Autism Spectrum Quotient (139) (measuring autistic traits) and the Introvertive Anhedonia subscale of the O-LIFE (140) were positively correlated, indicating a substantial association between autistic traits and social anhedonia in the general community. Similarly, adults with ASD were found to have significantly higher scores on the Social Anhedonia Scale (141) compared to their peers, even when dysphoric affect was controlled (142). In these studies, it is difficult to isolate social anhedonia specifically from other negative schizotypy traits (such as social anxiety) (130) or differentiate between the liking and wanting components of anhedonia. However, studies using alternative, well-validated measures of hedonic response have produced a similar pattern of results (143). For example, adolescents with ASD reported significantly less enjoyment of social situations (as measured with the Pleasure Scale) (144) compared to typical controls, while pleasure from other sources did not differ. Similarly, higher levels of autistic traits in a nonclinical sample were associated with less enjoyment of sociability (measured with the Social Reward Questionnaire) (109), even when differences in alexithymia were considered. In comparing psychiatric referrals for young people aged between 6 and 18 years, Gadow and Garman (145) found that those with ASD had higher rates of social anhedonia, while across all young people referred to the service, social anhedonia was related to higher social skill deficits, social anxiety, depression, and psychotic symptoms. This suggests that while social anhedonia might be present to some degree as a pediatric vulnerability marker for psychopathology, it appears to be more core to the presentation of ASD. Further studies are needed to understand the distinction between social anhedonia as a general risk factor for psychopathology and its presentation in ASD.

Of note, findings appear to indicate a specific problem of social anhedonia in adolescents (143), with broader reductions in social and nonsocial pleasure in adults with ASD $(132,143)$. However, this difference could be due to the types of measures employed or may be related to developmental factors and merits further investigation. If social anhedonia is a core feature of the broader autism phenotype, then why is this so? One possibility is that social anhedonia arises as a consequence of theory of mind deficits in people with ASD (e.g., difficulties in understanding the mental state of others make interactions less pleasurable) (146). Alternatively, experimental studies support the idea that a primary deficit in social motivation in ASD (linked to neuronal and hormonal circuitry) leads to difficulties seeking, experiencing, and learning about rewards from social interactions (147-150), leading to subsequent abnormalities in the development of the neural pathways underpinning reward and social functioning impairments. Again, however, while the motivation for social connection may be lower, the high rates of loneliness reported by people with ASD suggest that a basic need for some social bonds remains (151).

\section{GENETICS/NEURAL MECHANISMS AND NEURODEGENERATIVE DISORDERS}

While it is important to recognize social anhedonia's presentation in multiple clinical groups, it is essential to link social anhedonia through to its biological correlates. Understanding whether social anhedonia is underpinned by one mechanism that is consistent across all disorders or whether there are multiple pathways that can lead to the same outcome holds important treatment and etiological implications. Given that there are diverse neurological correlates underpinning the pleasure cycle (152), it may be that there are multiple biological pathways underpinning social anhedonia, which can account for its presentation in multiple disorders of distinct etiological mechanisms.

Certainly, multivariate studies from the general population have pointed to social anhedonia being genetically conferred $(153,154)$. Similarly, single nucleotide polymorphisms (SNPs) in genes implicated in neurodevelopment have been associated with social anhedonia along the psychosis continuum $(155,156)$. Building on these findings, two neurobiological pathways are thought to contribute to social anhedonia. The first emphasizes the role of dopamine in reward processes and social bonding (157). Evidence linking dopamine and social anhedonia can be drawn from genetic association studies in relatives of patients with schizophrenia (158) and dopamine D2 receptor binding availability along the psychosis continuum (159). Furthermore, in Parkinson's disease (characterized by the breakdown of dopamine-producing neurons), consummatory anhedonia is specifically blunted (160) independently of depression (161); however, social anhedonia is yet to receive specific attention.

A competing neurobiological hypothesis highlights the role of the opioid system in human affiliation and social bonding (162). The opioid system mediates both approach and avoidance behaviors in humans and animals. The opioid system has a role in fear consolidation and, therefore, may have specific relevance for the presence of social anhedonia in PTSD in particular (163). Evidence for the role of the opioid system in social anhedonia comes from genetic knockout and pharmacological models in mice (164) and a genetic association study in humans (165). However, the dopamine and opioid systems are also known to interact to underpin social bonding behaviors (166), with the nucleus accumbens providing an area of convergence for neural pathways (167). The DISC1-Q31L mutant mouse model is characterized by both abnormalities in nucleus accumbens structure and socially anhedonic-like behaviors (168). Together, these studies point to social bonding, reward processes, and social anhedonia being biologically mediated by both opioid and dopamine pathways.

The literature concerning the functional imaging correlates of social anhedonia is worthy of a review of its own. Because of space restrictions here, an overview of key and consistent 
findings will be given. Abnormal activity in the ventral lateral prefrontal cortex (VLPFC) has been the focus of work from one group of researchers in two related papers considering response to expected rewards $(169,170)$ and positive interpersonally relevant videos in a separate independent paper (171). In addition, Hooker et al. (171) found that those scoring highly on social anhedonia scales had lower levels of activity in the VLPFC and reported lower levels of positive affect during their daily lives. In addition, during a theory of mind task, activity in the medial prefrontal cortex accounted for the relationship between social anhedonia and self-reported social functioning (8). Reduced neural activity in face processing areas has been associated with social anhedonia during an emotional discrimination task (4), and smaller amygdala volumes have been related to higher social anhedonia scores in patients with schizophrenia (172). These studies suggest that brain areas involved in social cognition are associated with social anhedonia in clinical and healthy individuals.

Other imaging studies have examined the effective connectivity between brain areas in socially anhedonic individuals. Abnormal connectivity has been reported in adolescents (173), in those with depression (174), and in healthy volunteers $(8,175,176)$ who score highly on self-report measures of social anhedonia or anticipatory/consummatory anhedonia. These studies highlight the importance of connectivity between "emotional regulation" and "reward" centers within the brain. Contrastingly, Wang et al. (177) reported inverse correlations between social anhedonia and cortical thickness in the post central gyrus and left inferior parietal gyrus (after controlling for physical anhedonia) but no correlations with cortical thickness for areas involved in the reward network. At this time however, the implications of cortical thickness are poorly understood. On the other hand, Enneking et al. report that in both healthy volunteers and patients with depression, higher levels of social anhedonia were related to reduced gray matter volume in the bilateral caudate nucleus (178); these results remained controlling for other symptoms and medication status in the participants diagnosed with depression. The authors point to the role of the caudate nucleus in rewardbased learning and suggest it could account for difficulties in anticipating future rewards. This paper, perhaps, begins to suggest that the same neural substrates may underpin social anhedonia in healthy individuals as in patient groups. However, it does not address why social domains would be specifically affected by alterations in the caudate nucleus.

Genetic, neurobiological, and imaging studies collectively point to the importance of emotional regulation, reward circuitry, and social anhedonia. Such studies are only beginning to differentiate the wanting, liking, and learning components of social rewards; these psychological phenomena are complex manifestations of human desire/preference and hedonic in-themoment responses. Consequently, novel imaging paradigms will be needed to access the corresponding neural mechanisms. Certainly, imaging studies emphasize the importance of reward circuitry, the development and consolidation of which can be traced back to adolescence as a key window of sensitivity (179). Adolescence appears to represent a time when reward circuits are particularly sensitive to social context and peer experiences
$(180,181)$. This potentially points to the necessity to take into account social experiences and affiliations during adolescence to better understand the expression of social anhedonia in adults.

\section{DEVELOPMENTAL PERSPECTIVE}

Losing the desire or not experiencing pleasure in social interactions may have profound, negative consequences at any age. Currently, it is unclear at what age social anhedonia first presents, although notably, children at familial risk for developing psychosis present with poor social skills at all stages of development (182). Adolescence may be an especially important window to measure social anhedonia [e.g., Ref. (19)], since it is marked by considerable variability in neural, affective, and social development as well as peak vulnerability for psychopathology (183). Indeed, persistent, trait-like social anhedonia in early adolescence predicts increased severity of, and poorer recovery from, depression, above and beyond other illness features (184), while elevated levels of social anhedonia in older adolescents have been associated with an increased risk of developing schizophrenia spectrum disorders later in adulthood $(6,45)$. This suggests that age of first presentation of social anhedonia may have different implications for well-being. Importantly, the type of stimuli perceived to be rewarding changes throughout development. Acceptance and social inclusion by peers, for example, assume particular salience in early adolescents, while emerging adults may be more sensitive to intimacy cues, such as those from potential romantic partners (185). Conversely, various forms of social defeat have been linked to the onset of anhedonia, depression, anxiety, and schizophrenia (186-189). Together, the findings suggest that there may be normative, agerelated variations in the most prominent facets of social rewards within adolescence that require more detailed examination (190).

At the neural level, the cortical mechanisms involved in the processing of social and nonsocial rewards follow differential trajectories with age and gender, which can give rise to an imbalance between (heightened) motivation and (diminished) cognitive control during adolescence (191). Diminished activity in the ventral striatum in response to anticipation of monetary reward has been associated with anhedonia in adolescents, and ventral striatum activity in response to reward may be moderated by exposure to early life stress (192). These studies suggest that, like in adults, the ventral striatum is important in determining response to rewards, with social context, life experience, and expression of anhedonia mediating or moderating responsiveness. Few studies have focused on social reward and social anhedonia specifically. However, Healey et al. (173) reported that social anhedonia disrupted the neural response to social rewards: higher levels of activation in the medial prefrontal cortex and increased connectivity between the medial prefrontal cortex and the nucleus accumbens in response to positive social feedback were associated with higher levels of selfreported social anhedonia in adolescents. These results remained significant when other depressive symptoms were controlled for. Therefore, it appears that social anhedonia has quite specific effects on neural responses to rewards during adolescence. Much 
research has focused on response to reward during adolescence with regard to risk-taking behaviors, suicidality, substance use, and depression. However, specific consideration of social anhedonia, its consequences, and its relationship to social reward is lacking. Recent improvements in assessment (at self-report, behavioral, and neurophysiological levels) are beginning to offer a more detailed understanding of how social pleasure develops and goes awry $(193,194)$. For example, the Anticipatory and Consummatory Interpersonal Pleasure Scale for Adolescents (ACIPS-A) (19) measures the discrete wanting and liking component of reward and may help classify adolescents in the general community who are/are not at risk (e.g., of psychosis) (195) and may benefit from early intervention.

\section{GENERAL DISCUSSION}

\section{Comparison Across Different Diagnostic Groups}

Social anhedonia presents across multiple psychological disorders and is detectable to variable degree in the general healthy population (14). Across populations, it appears to have consequences for social enjoyment, affiliation, engagement, and functioning over and above any symptoms attributable to diagnosis. Specifically, decreased sensitivity to social rewards is documented in schizophrenia (61), eating disorders (93), PTSD (118), and autism spectrum disorders (146). Social anhedonia, specifically, may present as a trait temperament characteristic in some individuals, while for others, it may be linked to the co-occurrence of depressive symptomatology. For instance, in patients with schizophrenia and bipolar disorder, depression (rather than cognitive functioning) has been reported to predict social anhedonia (196). The wider presentation of anhedonia also needs to be considered as a backdrop for social anhedonia. In some disorders (i.e., eating disorders), anhedonia is present but generalized across both social and nonsocial domains, while for others, such as PTSD, anhedonia may be relatively specific to social environments and interactions. Studies are also required comparing differing levels of social anhedonia across different diagnostic groups. Currently, some studies report that patients with active depression score higher than patients with schizophrenia on social anhedonia (69), while others report that patients with schizophrenia score higher than those with bipolar disorder, who both score higher than healthy controls (196). Across all studies, patient groups, regardless of diagnosis, report higher levels of social anhedonia compared to healthy controls, although it needs to be noted that the psychosis continuum work highlights wide variation in social anhedonia scores in healthy volunteer samples. Fine-grained consideration of anticipatory and consummatory components also needs consistent consideration across diagnostic groups. Broadly speaking, the psychosis continuum seems to be characterized by deficits in anticipatory but not consummatory systems (although not consistently) (59), while PTSD (121), depression (74), and ASD reflect difficulties in both and the picture for eating disorders appears to be complex with inconsistent findings reflecting symptom and etiological heterogeneity. In increasing our understanding of social anhedonia it is important to understand whether its presentation differs when it occurs in the presence of broader anhedonia compared to the specific subtype of social contexts, cues, and environments. Indeed, social anhedonia is complex: it is defined by and captures both observable social behaviors and subjective hedonic responses.

Although the exploration of anticipatory and consummatory reward begins to explicate the complex nature of reward in psychiatric conditions, we need to specifically consider these in relation to social anhedonia within and between different groups. The processing of reward is related to social anhedonia; however, the experience of and processes underpinning reward are not interchangeable with social anhedonia. Within each diagnostic group (and indeed in healthy populations), those who express social anhedonia are a subgroup (70) whose hedonic and reward responses likely differ from their counterparts. We must not confuse the processes underpinning social anhedonia as interchangeable with its phenotypic characterization. Stated differently, we need to better understand exactly what the mechanisms are underpinning the expression of social anhedonia and how these vary across diagnostic groups. Furthermore, there is increasing emphasis on the anticipatory and consummatory components of reward; however, the learning component of the pleasure cycle has been relatively underresearched in relation to social anhedonia.

\section{Psychometric and Measurement Issues}

There are now a number of measures used in this area that varyingly capture social anhedonia as a trait, anticipatory and consummatory pleasure, social reward, and pleasure responses in general. While studies considering pleasure and reward provide information about the processes that underpin social anhedonia, they are not interchangeable with the use of trait measures such as the RSAS. Further psychometric work is needed to understand the shared variance between these measures. For instance, Gooding et al. (197) have reported that different aspects of personality predict scores on the ACIPS and the RSAS, suggesting subtle differences in what these two scales capture despite both being measures of social anhedonia. Furthermore, we need to begin to devise smart validity studies providing links to emotional and behavioral manifestations of social anhedonia.

There are two other, highly related, points that arise in consideration of the findings within this area. The first is the quality of studies on social anhedonia. These are largely correlational or observational in nature, regardless of whether they are considering clinical or nonclinical samples. Currently, there are no recognized clinically relevant cutoffs for most of the measures used in this field to distinguish functional versus dysfunctional levels of social anhedonia. This is particularly problematic when considering the variability in results in the psychosis continuum literature work; it may be the largest body of work on social anhedonia, but it is also the most inconsistent with its findings. Clinical cutoffs for measures would start to tease apart whether the levels of social anhedonia 
being expressed across different diagnostic groups, as well as between healthy volunteers and diagnostic groups, are similar in nature. In addition, a parallel issue is the necessity to begin to understand at what level social anhedonia begins to impact functioning; this, again, is equally important to healthy volunteer studies as well as clinical studies. In fact, if we can understand at what point levels of social anhedonia begin to impact social functioning in healthy volunteers, we will be able to begin to unpick whether social anhedonia or other symptomatology is driving social functioning deficits in those who do have a primary diagnosis.

The self-report nature of the scales used in research on social anhedonia also relies on the level of self-awareness that people have about their own thoughts, feelings, and behaviors in social interactions, and motivations for interpersonal communication. This is clearly problematic, particularly once we begin to consider the effects of mental health disorders on self-awareness. There is increasing evidence for subjective deficits in self (emotion) regulation in social anhedonia, while objective performance remains intact (198); these subjective deficits, however, would be sufficient to bias the processing of social information. In addition, low pleasure beliefs are documented in relation to social anhedonia (199), and these low pleasure beliefs appear to play a role in predicting the likelihood that future pleasurable events will occur (200). These studies point to there being cognitive biases related to social anhedonia, which could influence the likelihood of similarly biased responding on social report scales. The possibility that biases could shape responses also goes back to the paradoxical relationship between social anhedonia and loneliness and the number of studies that demonstrated those with social anhedonia do engage in significant social relationships: If those with social anhedonia do not gain pleasure or reward from social interactions, then why do they appear to experience negative consequences from the absence of affiliative experiences? Perhaps, we are currently missing important information about the processing of social interactions and the subjective gain from them by relying on predominantly selfreport data within the area of social anhedonia.

There are some innovative studies within this area, however, that do attempt to address the potential for poor social awareness in social situations in those who express social anhedonia. A series of studies by Blanchard and colleagues $(38,47,53,65)$ uses a paradigm whereby participants interact with an experimenter who rates their social interaction as well as the participant rating the social interaction. This permits the marrying of perceptions of social engagement and interaction style with ratings reflecting the subjective and (more) objective experience ratings. More studies are needed that make use of behavioral indicators and measures of social behaviors for social anhedonia alongside reliable and valid self-report scales.

Interestingly, a number of more recently published studies are using the term "negative schizotypy" to capture social anhedonia. Negative schizotypy is a broader construct than merely social anhedonia and also encapsulates social anxiety, flattened affect, and anhedonia in general. Therefore, care needs to be taken in a consistent use of terminology so that it is clear from the outset what constructs have been measured to ensure that the significance of the results can be clearly appreciated. Furthermore, social anhedonia needs consideration as a distinct form of anhedonia-with separable neural substrates (201). When considering the clinical end point of schizophrenia, work is emerging that anhedonia is a distinct feature of negative symptoms worthy of consideration (202). Indeed, future research needs to consider whether social anhedonia is distinct from other symptoms of psychiatric diagnoses. Similarly, recent studies have examined whether social anhedonia is a separable construct from other schizotypal traits. Support for this proposal comes from recent psychometric work, which revealed that negative affect and social anhedonia load on separate dimensions of the broader schizotypy construct (203), while other works suggest that social anhedonia loads onto both positive and negative features of schizotypy $(204,205)$. Therefore, further empirical evidence is needed to better understand the relation of social anhedonia to other schizotypal traits and to other mental health disorders considered here.

\section{Future Directions and Conclusions}

Social interactions are the most complex and ambiguous environments human beings place themselves in. Many explicit and implicit "rules" govern what is considered appropriate and what can be expected from any one interaction. Consequently, they are settings rife for miscommunication and misunderstanding. It requires intricate examination to determine exactly what the rewarding components of social interactions are. Social interactions are highly dynamic, complex circumstances that seem more inclined to produce anxiety than lead to rewards given their ambiguities. For those with social anhedonia, whose sensitivity to the positive gains from social interactions may be limited, it is easy to see why relationships might be considered best avoided. Individuals with social anhedonia may require larger perceived gains before they engage in social approach behaviors. We currently have a poor understanding of how social anhedonia relates to social motivation [e.g., Ref. (38)]. However, studies point to those with social anhedonia seeking out personal relationships, albeit with reduced positive experiences (31); therefore, those with social anhedonia have some motivation for belongingness and are aware when belongingness needs are unmet (i.e., they feel lonely). A greater understanding of the perceived rewards from social interactions and interpersonal relationships would assist in determining what motivates people to make connections with one another. It is becoming particularly important to understand this given the emerging body of work demonstrating the detrimental effects of loneliness and social disconnection on physical and mental health $(3,64,206)$.

Currently, there is limited understanding of the neurodevelopmental origins of social anhedonia or the differences in social anhedonia experienced earlier (e.g., as a personality trait) versus later in life (e.g., in the context of adult-onset disorder). The neurobiological and neural correlates implicated in emotional regulation and reward provide likely key biological pathways for social anhedonia. Adolescence represents a key window of vulnerability given that reward processing and 
social needs undergo maturational changes $(207,208)$. The psychological (e.g., temperament, mood), learning (e.g., stresses, life e vents, trauma, attachment), and cognitive (e.g., anticipatory and consummatory reward) correlates of social anhedonia require exploration in children and adolescents. The socialization of reward processes may represent a point of psychological vulnerability (209), particularly how children learn to express and receive reward from social interactions. Understanding how reward from social interactions is gained will not only assist in understanding the development of social anhedonia but may also

\section{REFERENCES}

1. Baumeister RF, Leary MR. The need to belong: desire for interpersonal attachments as a fundamental human motivation. Psychol Bull (1995) 117:497-529. doi: 10.1037/0033-2909.117.3.497

2. DeWall CN, Deckman T, Pond RS, Jr., Bonser I. Belongingness as a core personality trait: how social exclusion influences social functioning and personality expression. J Pers (2011) 79:1281-314. doi: 10.1111/j.1467-6494.2010.00695.x

3. Cacioppo S, Grippo AJ, London S, Goossens L, Cacioppo JT. Loneliness: clinical import and interventions. Perspect Psychol Sci (2015) 10:238-49. doi: $10.1177 / 1745691615570616$

4. Germine LT, Garrido L, Bruce L, Hooker C. Social anhedonia is associated with neural abnormalities during face emotion processing. Neuroimage (2011) 58:935-45. doi: 10.1016/j.neuroimage.2011.06.059

5. Blanchard JL, Horan WP, Brown SA. Diagnostic differences in social anhedonia: A longitudinal study of schizophrenia and major depressive disorder. J Abnorm Child Psychol (2001) 110:363-71. doi: 10.1037/0021-843X.110.3.363

6. Kwapil TR. Social anhedonia as a predictor of the development of schizophrenia-spectrum disorders. J Abnorm Psychol (1998) 107:558-65. doi: 10.1037/0021-843X.107.4.558

7. Kwapil TR, Silvia PJ, Myin-Germeys I, Anderson AJ, Coates SA, Brown LH. The social world of the socially anhedonic: exploring the daily ecology of asociality. J Res Pers (2009) 43:103-6. doi: 10.1016/j.jrp.2008.10.008

8. Dodell-Feder D, Tully LM, Lincoln SH, Hooker CI. The neural basis of theory of mind and its relationship to social functioning and social anhedonia in individuals with schizophrenia. Neuroimage Clin (2014) 4:154-63. doi: 10.1016/j.nicl.2013.11.006

9. Silvia PJ, Kwapil TR. Aberrant asociality: how individual differences in social anhedonia illuminate the need to belong. J Pers (2011) 79:1315-32. doi: 10.1111/j.1467-6494.2010.00702.x

10. Martin EA, Cicero DC, Bailey DH, Karcher NR, Kerns JG. Social anhedonia is not just extreme introversion: empirical evidence of distinct constructs. J Pers Disord (2016) 30:451-68. doi: 10.1521/pedi_2015_29_203

11. Olino TM, Horton LE, Versella MV. A comparison of psychometric and convergent validity for social anhedonia and social closeness. Psychol Assess (2016) 28:1465-74. doi: 10.1037/pas0000291

12. Gooding DC, Tallent KA, Matts CW. Clinical status of at-risk individuals 5 years later: further validation of the psychometric high-risk strategy. J Abnorm Child Psychol (2005) 114:170-5. doi: 10.1037/0021-843X.114.1.170

13. Gooding DC, Tallent KA, Matts CW. Rates of avoidant, schizotypal, schizoid and paranoid personality disorders in psychometric high-risk groups at 5-year follow-up. Schizophr Res (2007) 94:373-4. doi: 10.1016/j. schres.2007.04.018

14. Miettunen J, Isohanni M, Paunio T, Freimer N, Taanila A, Ekelund J, et al. Predicting depression with psychopathology and temperament traits: the northern Finland 1966 birth cohort. Depress Res Treat (2012) 2012:160905. doi: 10.1155/2012/160905

15. Foulkes L, Viding E, McCrory E, Neumann CS. Social Reward Questionnaire (SRQ): development and validation. Front Psychol (2014) 5:201. doi: 10.3389/ fpsyg.2014.00201 begin to elucidate the reason social connections buffer physical and mental health (210).

\section{AUTHOR CONTRIBUTIONS}

$\mathrm{EB}$ and JB both conducted the literature searches that generated the papers to be included. Both authors contributed to the text within the manuscript and edited different versions. EB integrated the manuscript to ensure consistency in approach and style of writing.

16. Fawcett J, Clark DC, Scheftner WA, Gibbons RD. Assessing anhedonia in psychiatric patients. Arch Gen Psychiatry (1983) 40:79-84. doi: 10.1001/ archpsyc.1983.01790010081010

17. Gard DE, Gard MG, Kring AM, John OP. Anticipatory and consummatory components of the experience of pleasure: a scale development study. J Res Pers (2006) 40:1086-102. doi: 10.1016/j.jrp.2005.11.001

18. Gooding DC, Pflum MJ. The assessment of interpersonal pleasure: introduction of the Anticipatory and Consummatory Interpersonal Pleasure Scale (ACIPS) and preliminary findings. Psychiatry Res (2014) 215:237-43. doi: 10.1016/j.psychres.2013.10.012

19. Gooding DC, Pflum MJ, Fonseca-Pedero E, Paino M. Assessing social anhedonia in adolescence: the ACIPS-A in a community sample. Eur. Psychiatry (2016) 37:49-55. doi: 10.1016/j.eurpsy.2016.05.012

20. Kirkpatrick B, Strauss GP, Nguyen L, Fischer BA, Daniel DG, Cienfuegos A, et al. The Brief Negative Symptom Scale: psychometric properties. Schizophr Bull (2011) 37:300-5. doi: 10.1093/schbul/sbq059

21. Snaith RP, Hamilton M, Morley S, Humayan A, Hargreaves D, Trigwell P. A scale for the assessment of hedonic tone the Snaith-Hamilton Pleasure Scale. Br J Psychiatry (1995) 167:99-103. doi: 10.1192/bjp.167.1.99

22. Horan WP, Green MF, Kring AM, Nuechterlein KH. Does anhedonia in schizophrenia reflect faulty memory for subjectively experienced emotions? J Abnorm Child Psychol (2006) 115:496-508. doi: 10.1037/0021-843X.115. 3.496

23. Berridge KC. Reward learning: reinforcement, incentives, and expectations. Psychol Learn Motiv (2001) 40:223-78. doi: 10.1016/S0079-7421(00)80022-5

24. Berridge $\mathrm{KC}$. The debate over dopamine's role in reward: the case for incentive salience. Psychopharmacology (2007) 191:391-431. doi: 10.1007/ s00213-006-0578-x

25. Smith KS, Berridge KC. Opioid limbic circuit for reward: interaction between hedonic hotspots of nucleus accumbens and ventral pallidum. J Neurosci (2007) 27:1594-605. doi: 10.1523/JNEUROSCI.4205-06.2007

26. Peciña S, Berridge KC. Hedonic hot spot in nucleus accumbens shell: where do $\mu$-Opioids cause increased hedonic impact of sweetness? J Neurosci (2005) 25:11777-86. doi: 10.1523/JNEUROSCI.2329-05.2005

27. Berridge KC, Kringelbach ML. Affective neuroscience of pleasure: reward in humans and animals. Psychopharmacology (2008) 199:457-80. doi: 10.1007/ s00213-008-1099-6

28. Treadway MT, Zald DH. Reconsidering anhedonia in depression: lessons from translational neuroscience. Neurosci Biobehav Rev (2011) 35:537-55. doi: 10.1016/j.neubiorev.2010.06.006

29. Romer Thomsen K, Whybrow PC, Kringelbach ML. Reconceptualizing anhedonia: novel perspectives on balancing the pleasure networks in the human brain. Front Behav Neurosci (2015) 9:49. doi: 10.3389/ fnbeh.2015.00049

30. Brown LH, Silvia PJ, Myin-Germeys I, Kwapil TR. When the need to belong goes wrong: the expression of social anhedonia and social anxiety in daily life. Psychol Sci (2007) 18:778-82. doi: 10.1111/j.1467-9280.2007.01978.x

31. Assaad L, Lemay EP, Jr. Social anhedonia and romantic relationship processes. J Pers (2016) 86(2):147-57. doi: 10.1111/jopy.12300|

32. Gutkovich Z. Anhedonia in children and adolescents. In: RM Anhedonia: a comprehensive handbook Volume I. Dordrecht: Springer (2014). doi: 10.1007/978-94-017-8591-4_4 
33. Shevlin M, Murphy J, Dorahy MJ, Adamson G. The distribution of positive psychosis-like symptoms in the population: a latent class analysis of the National Comorbidity Survey. Schizophr Res (2007) 89:101-9. doi: 10.1016/j. schres.2006.09.014

34. Thomas EH, Rossell SL, Tan EJ, Neill E, Van Rheenen TE, Carruthers SP, et al. Do schizotypy dimensions reflect the symptoms of schizophrenia? Aust N Z J Psychiatry (2018) 53(3):236-47. doi: 10.1177/0004867418769746

35. Fonseca-Pedrero E. GDC, Paino M, Lemos-Giráldez S, Muñiz J. Measuring anhedonia in schizophrenia-spectrum disorders: a selective update. In: Ritsner M Anhedonia: a comprehensive handbook Volume II. Dordrecht: Springer (2014). doi: 10.1007/978-94-017-8610-2_2

36. Blanchard JJ, Collins LM, Aghevli M, Leung WW, Cohen AS. Social anhedonia and schizotypy in a community sample: the Maryland longitudinal study of schizotypy. Schizophr Bull (2011) 37:587-602. doi: 10.1093/schbul/sbp107

37. Mishlove M, Chapman LJ. Social anhedonia in the prediction of psychosis proneness. J Abnorm Psychol (1985) 94:384-96. doi: 10.1037/ 0021-843X.94.3.384

38. Llerena K, Park SG, Couture SM, Blanchard JJ. Social anhedonia and affiliation: examining behavior and subjective reactions within a social interaction. Psychiatry Res (2012) 200:679-86. doi: 10.1016/j.psychres.2012.07.050

39. Badcock JC, Barkus E, Cohen AS, Bucks R, Badcock DR. Loneliness and schizotypy are distinct constructs, separate from general psychopathology. Front Psychol (2016) 7:1018. doi: 10.3389/fpsyg.2016.01018

40. Cohen AS, Couture SM, Blanchard JJ. Neuropsychological functioning and social anhedonia: three-year follow-up data from a longitudinal community high risk study. J Psychiatr Res (2012) 46:898-904. doi: 10.1016/j. jpsychires.2012.03.020

41. Tully LM, Lincoln SH, Hooker CI. Attentional control mediates the relationship between social anhedonia and social impairment. Front Psychol (2014) 5:1384. doi: 10.3389/fpsyg.2014.01384

42. Pflum MJ, Gooding DC. Context matters: social cognition task performance in psychometric schizotypes. Psychiatry Res (2018) 264:398-403. doi: 10.1016/j.psychres.2018.03.075

43. Li X, Li Z, Li K, Zeng YW, Shi HS, Xie WL, et al. The neural transfer effect of working memory training to enhance hedonic processing in individuals with social anhedonia. Sci Rep (2016) 6:35481. doi: 10.1038/srep35481

44. Li X, Xiao YH, Zou LQ, Li HH, Yang ZY, Shi HS, et al. The effects of working memory training on enhancing hedonic processing to affective rewards in individuals with high social anhedonia. Psychiatry Res (2016) 245:482-90. doi: 10.1016/j.psychres.2016.09.006

45. Kwapil TR, Gross GM, Silvia PJ, Barrantes-Vidal N. Prediction of psychopathology and functional impairment by positive and negative schizotypy in the Chapmans' ten-year longitudinal study. J Abnorm Child Psychol (2013) 122:807-15. doi: 10.1037/a0033759

46. Tarbox-Berry SI, Perkins DO, Woods SW, Addington J. Premorbid social adjustment and association with attenuated psychotic symptoms in clinical high-risk and help-seeking youth. Psychol Med (2017) 48(6):983-97. doi: 10. 1017/S0033291717002343

47. McCarthy JM, Bradshaw KR, Catalano LT, Garcia CP, Malik A, Bennett ME, et al. Negative symptoms and the formation of social affiliative bonds in schizophrenia. Schizophr Res (2018) 193:225-31. doi: 10.1016/j.schres.2017.07.034

48. Ahmed AO, Murphy CF, Latoussakis V, McGovern KE, English J, Bloch A, et al. An examination of neurocognition and symptoms as predictors of posthospital community tenure in treatment resistant schizophrenia. Psychiatry Res (2016) 236:47-52. doi: 10.1016/j.psychres.2016.01.001

49. Ritsner MS, Ratner Y, Mendyk N, Gooding DC. The characterization of social anhedonia and its correlates in schizophrenia and schizoaffective patients. Psychiatry Res (2018) 270:922-8. doi: 10.1016/j.psychres.2018.11.003

50. Martin EA, Cicero DC, Kerns JG. Social anhedonia, but not positive schizotypy, is associated with poor affective control. Pers Disord (2012) 3:263-72. doi: 10.1037/a0024488

51. Tully LM, Lincoln SH, Hooker CI. Impaired executive control of emotional information in social anhedonia. Psychiatry Res (2012) 197:29-35. doi: 10.1016/j.psychres.2011.12.023

52. Kerns JG, Docherty AR, Martin EA. Social and physical anhedonia and valence and arousal aspects of emotional experience. J Abnorm Psychol (2008) 117:735-46. doi: 10.1037/a0013601
53. Leung WW, Couture SM, Blanchard JJ, Lin S, Llerena K. Is social anhedonia related to emotional responsivity and expressivity? A laboratory study in women. Schizophr Res (2010) 124:66-73. doi: 10.1016/j.schres.2010.06.012

54. Mathews JR, Barch DM. Episodic memory for emotional and non-emotional words in individuals with anhedonia. Psychiatry Res (2006) 143:121-33. doi: 10.1016/j.psychres.2005.07.030

55. Harvey PO, Bodnar M, Sergerie K, Armony J, Lepage M. Relation between emotional face memory and social anhedonia in schizophrenia. J Psychiatry Neurosci (2009) 34:102-10.

56. Schultze-Lutter F. Subjective symptoms of schizophrenia in research and the clinic: the basic symptom concept. Schizophr Bull (2009) 35:5-8. doi: $10.1093 / \mathrm{schbul} / \mathrm{sbn} 139$

57. Fortunati R, Ossola P, Camerlengo A, Bettini E, De Panfilis C, Tonna M, et al. Anhedonia in schizophrenia: the role of subjective experiences. Compr Psychiatry (2015) 62:152-60. doi: 10.1016/j.comppsych.2015.07.011

58. Whitton AE, Treadway MT, Pizzagalli DA. Reward processing dysfunction in major depression, bipolar disorder and schizophrenia. Curr Opin Psychiatry (2015) 28:7-12. doi: 10.1097/YCO.0000000000000122

59. Gard DE, Kring AM, Gard MG, Horan WP, Green MF. Anhedonia in schizophrenia: distinctions between anticipatory and consummatory pleasure. Schizophr Res (2007) 93:253-60. doi: 10.1016/j.schres. 2007.03.008

60. Chevallier C, Tonge N, Safra L, Kahn D, Kohls G, Miller J, et al. Measuring social motivation using signal detection and reward responsiveness. PLoS One (2016) 11:e0167024. doi: 10.1371/journal.pone.0167024

61. Xie WZ, Yan C, Ying XY, Zhu SY, Shi HS, Wang Y, et al. Domain-specific hedonic deficits towards social affective but not monetary incentives in social anhedonia. Sci Rep (2014) 4:4056. doi: 10.1038/srep04056

62. Henry JD, Green MJ, de Lucia A, Restuccia C, McDonald S, O’Donnell M. Emotion dysregulation in schizophrenia: Reduced amplification of emotional expression is associated with emotional blunting. Schizophr Res (2007) 95:197-204. doi: 10.1016/j.schres.2007.06.002

63. Gold JM, Waltz JA, Prentice KJ, Morris SE, Heerey EA. Reward processing in schizophrenia: a deficit in the representation of value. Schizophr Bull (2008) 34:835-47. doi: 10.1093/schbul/sbn068

64. Badcock JC, Shah S, Mackinnon A, Stain HJ, Galletly C, Jablensky A, et al. Loneliness in psychotic disorders and its association with cognitive function and symptom profile. Schizophr Res (2015) 169:268-73. doi: 10.1016/j. schres.2015.10.027

65. Blanchard JJ, Park SG, Catalano LT, Bennett ME. Social affiliation and negative symptoms in schizophrenia: examining the role of behavioral skills and subjective responding. Schizophr Res (2015) 168:491-7. doi: 10.1016/j. schres.2015.07.019

66. Tremeau F, Antonius D, Todorov A, Rebani Y, Ferrari K, Lee SH, et al. What can the study of first impressions tell us about attitudinal ambivalence and paranoia in schizophrenia? Psychiatry Res (2016) 238:86-92. doi: 10.1016/j. psychres.2016.02.014

67. Wang J, Huang J, Lui SSY, Cheung EFC, Yue XD, Chan RCK. Motivation deficits in individuals with social anhedonia. Psychiatry Res (2018) 261:52734. doi: $10.1016 /$ j.psychres.2018.01.033

68. Hasler G, Drevets WC, Manji HK, Charney DS. Discovering endophenotypes for major depression. Neuropsychopharmacology (2004) 29:1765. doi: 10.1038/ sj.npp. 1300506

69. Olsen EK, Bjorkquist OA, Bodapati AS, Shankman SA, Herbener ES. Associations between trait anhedonia and emotional memory deficits in females with schizophrenia versus major depression. Psychiatry Res (2015) 230:323-30. doi: 10.1016/j.psychres.2015.09.012

70. Pelizza L, Ferrari A. Anhedonia in schizophrenia and major depression: state or trait? Ann Gen Psychiatry (2009) 8:22. doi: 10.1186/1744-859X-8-22

71. Rey G, Jouvent R, Dubal S. Schizotypy, depression, and anxiety in physical and social anhedonia. J Clin Psychology (2009) 65:695-708. doi: 10.1002/ jclp. 20577

72. Atherton BD, Nevels RM, Moore MT. Predicting symptoms of depression from social anhedonia and emotion regulation. J Nerv Ment Dis (2015) 203:170-4. doi: 10.1097/NMD.0000000000000262

73. Gorwood P. Neurobiological mechanisms of anhedonia. Dialogues Clin Neurosci (2008) 10:291-9. 
74. Sherdell L, Waugh CE, Gotlib IH. Anticipatory pleasure predicts motivation for reward in major depression. J Abnorm Child Psychol (2012) 121:51-60. doi: $10.1037 / \mathrm{a} 0024945$

75. Setterfield M, Walsh M, Frey AL, McCabe C. Increased social anhedonia and reduced helping behaviour in young people with high depressive symptomatology. J Affect Disord (2016) 205:372-7. doi: 10.1016/j.jad.2016.08.020

76. Schwartz-Mette RA, Rose AJ. Depressive symptoms and conversational selffocus in adolescents' friendships. J Abnorm Child Psychol (2016) 44:87-100. doi: 10.1007/s10802-015-9980-3

77. Girard JM, Cohn JF, Mahoor MH, Mavadati S, Rosenwald DP. Social risk and depression: evidence from manual and automatic facial expression analysis. Proceedings of the International Conference on Automatic Face and Gesture Recognition IEEE International Conference on Automatic Face \& Gesture Recognition (2013) 1-8. doi: 10.1109/FG.2013.6553748

78. Kadison LS, Ragsdale KA, Mitchell JC, Cassisi JE, Bedwell JS. Subtypes of anhedonia and facial electromyography response to negative affective pictures in non-psychiatric adults. Cogn Neuropsychiatry (2015) 20:31-40. doi: 10.1080/13546805.2014.955172

79. Zhang YJ, Wang HY, Yan C, Wang LL, Cheung EFC, Chan RCK. Working memory training can improve anhedonia in college students with subsyndromal depressive symptoms. Psychiatry J (2019) doi: 10.1002/pchj.271

80. Kollias CT, Kontaxakis VP, Havaki-Kontaxaki BJ, Stamouli S, Margariti M, Petridou E. Association of physical and social anhedonia with depression in the acute phase of schizophrenia. Psychopathology (2008) 41:365-70. doi: $10.1159 / 000152378$

81. Katsanis J, Iacono WG, Beiser M, Lacey L. Clinical correlates of anhedonia and perceptual aberration in first-episode patients with schizophrenia and affective disorder. J Abnorm Psychol (1992) 101:184-91. doi: 10.1037/ 0021-843X.101.1.184

82. Berridge KC, Ho C-Y, Richard JM, DiFeliceantonio AG. The tempted brain eats: pleasure and desire circuits in obesity and eating disorders. Brain Res (2010) 1350:43-64. doi: 10.1016/j.brainres.2010.04.003

83. Steinglass JE, Berner LA, Attia E. Cognitive neuroscience of eating disorders. Psychiatr Clin North Am (2019) 42:75-91. doi: 10.1016/j.psc.2018.10.008

84. Avena NM, Bocarsly ME. Dysregulation of brain reward systems in eating disorders: neurochemical information from animal models of binge eating, bulimia nervosa, and anorexia nervosa. Neuropharmacology (2012) 63:8796. doi: 10.1016/j.neuropharm.2011.11.010

85. Berner LA, Brown TA, Lavender JM, Lopez E, Wierenga CE, Kaye WH. Neuroendocrinology of reward in anorexia nervosa and bulimia nervosa: beyond leptin and ghrelin. Mol Cell Endocrinol (2018). doi: 10.1016/j. mce.2018.10.018

86. Monteleone AM, Castellini G, Volpe U, Ricca V, Lelli L, Monteleone P, et al. Neuroendocrinology and brain imaging of reward in eating disorders: a possible key to the treatment of anorexia nervosa and bulimia nervosa. Prog Neuropsychopharmacol Biol Psychiatry (2018) 80:132-42. doi: 10.1016/j. pnpbp.2017.02.020

87. Dunlop KA, Woodside B, Downar J. Targeting neural endophenotypes of eating disorders with non-invasive brain stimulation. Front Neurosci (2016) 10:30. doi: 10.3389/fnins.2016.00030

88. Keating C. Theoretical perspective on anorexia nervosa: the conflict of reward. Neurosci Biobehav Rev (2010) 34:73-9. doi: 10.1016/j.neubiorev.2009.07.004

89. O'Hara CB, Campbell IC, Schmidt U. A reward-centred model of anorexia nervosa: a focussed narrative review of the neurological and psychophysiological literature. Neurosci Biobehav Rev (2015) 52:131-52. doi: 10.1016/j.neubiorev.2015.02.012

90. Keating C, Tilbrook AJ, Rossell SL, Enticott PG, Fitzgerald PB. Reward processing in anorexia nervosa. Neuropsychologia (2012) 50:567-75. doi: 10.1016/j.neuropsychologia.2012.01.036

91. Treasure J, Corfield F, Cardi V. A three-phase model of the social emotional functioning in eating disorders. Eur Eat Disord Rev (2012) 20:431-8. doi: 10.1002/erv.2181

92. Caglar-Nazali HP, Corfield F, Cardi V, Ambwani S, Leppanen J, Olabintan O, et al. A systematic review and meta-analysis of 'Systems for Social Processes' in eating disorders. Neurosci Biobehav Rev (2014) 42:55-92. doi: 10.1016/j. neubiorev.2013.12.002

93. Cardi V, Di Matteo R, Corfield F, Treasure J. Social reward and rejection sensitivity in eating disorders: an investigation of attentional bias and early experiences. World J Biol Psychiatry (2013) 14:622-33. doi: $10.3109 / 15622975.2012 .665479$

94. Oldershaw A, Hambrook D, Stahl D, Tchanturia K, Treasure J, Schmidt U. The socio-emotional processing stream in Anorexia Nervosa. Neurosci Biobehav Rev (2011) 35:970-88. doi: 10.1016/j.neubiorev.2010.11.001

95. Treasure J, Schmidt U. The cognitive-interpersonal maintenance model of anorexia nervosa revisited: a summary of the evidence for cognitive, socioemotional and interpersonal predisposing and perpetuating factors. $J$ Eat Disord (2013) 1:13. doi: 10.1186/2050-2974-1-13

96. Tchanturia K, Davies H, Harrison A, Fox JR, Treasure J, Schmidt U. Altered social hedonic processing in eating disorders. Int J Eat Disord (2012) 45:962-9. doi: 10.1002/eat.22032

97. Harrison A, Mountford VA, Tchanturia K. Social anhedonia and work and social functioning in the acute and recovered phases of eating disorders. Psychiatry Res (2014) 218:187-94. doi: 10.1016/j.psychres.2014.04.007

98. Deborde AS, Berthoz S, Godart N, Perdereau F, Corcos M, Jeammet P. [Relations between alexithymia and anhedonia: a study in eating disordered and control subjects]. Encephale (2006) 32:83-91. doi: 10.1016/S0013-7006(06)76140-1

99. Eiber R, Berlin I, de Brettes B.t., Foulon C, Guelfi JD. Hedonic response to sucrose solutions and the fear of weight gain in patients with eating disorders. Psychiatry Res (2002) 113:173-80. doi: 10.1016/S0165-1781(02)00232-9

100. Watson KK, Werling DM, Zucker NL, Platt ML. Altered social reward and attention in anorexia nervosa. Front Psychol (2010) 1:36. doi: 10.3389/ fpsyg.2010.00036

101. McAdams CJ, Lohrenz T, Montague PR. Neural responses to kindness and malevolence differ in illness and recovery in women with anorexia nervosa. Hum Brain Mapp (2015) 36:5207-19. doi: 10.1002/hbm.23005

102. Via E, Soriano-Mas C, Sánchez I, Forcano L, Harrison BJ, Davey CG, et al. Abnormal social reward responses in anorexia nervosa: an fMRI study. PLoS One (2015) 10:e0133539. doi: 10.1371/journal.pone.0133539

103. Tchanturia K, Doris E, Mountford V, Fleming C. Cognitive Remediation and Emotion Skills Training (CREST) for anorexia nervosa in individual format: self-reported outcomes. BMC Psychiatry (2015) 15:53. doi: 10.1186/ s12888-015-0434-9

104. Tchanturia K, Doris E, Fleming C. Effectiveness of cognitive remediation and emotion skills training (CREST) for anorexia nervosa in group format: a naturalistic pilot study. Eur Eat Disord Rev (2014) 22:200-5. doi: 10.1002/ erv.2287

105. Westwood H, Mandy W, Tchanturia K. Clinical evaluation of autistic symptoms in women with anorexia nervosa. Mol Autism (2017) 8:12. doi: 10.1186/s13229-017-0128-x

106. Westwood H, Tchanturia K. Autism spectrum disorder in anorexia nervosa: an updated literature review. Curr Psychiatry Rep (2017) 19:41. doi: 10.1007/ s11920-017-0791-9

107. Alves Pereira C, Silva JR, Cajão R, Lourenço JP, Casanova T. The co-occurrence of eating disorders and psychosis. Eur Psychiatry (2016) 33:S425. doi: 10.1016/j.eurpsy.2016.01.1540

108. Adamson J, Leppanen J, Murin M, Tchanturia K. Effectiveness of emotional skills training for patients with anorexia nervosa with autistic symptoms in group and individual format. Eur Eat Disord Rev (2018) 26:367-75. doi: 10.1002/erv.2594

109. Foulkes L, Bird G, Gökçen E, McCrory E, Viding E. Common and distinct impacts of autistic traits and alexithymia on social reward. PLoS One (2015) 10:e0121018. doi: 10.1371/journal.pone.0121018

110. American Psychiatric Association. Diagnostic and statistical manual of mental disorders: DSM 5. Washington DC: American Psychiatric Pub Incorporated (2013).

111. Mitchell KS, Wolf EJ, Bovin MJ, Lee LO, Green JD, Rosen RC, et al. Network models of DSM-5 posttraumatic stress disorder: Implications for ICD-11. J Abnorm Psychol (2017) 126:355-66. doi: 10.1037/abn0000252

112. Kashdan TB, Elhai JD, Frueh BC. Anhedonia and emotional numbing in combat veterans with PTSD. Behav Res Ther (2006) 44:457-67. doi: 10.1016/j. brat.2005.03.001

113. Powers A, Fani N, Cross D, Ressler KJ, Bradley B, Childhood trauma PTSD. and psychosis: findings from a highly traumatized, minority sample. Child Abuse Negl (2016) 58:111-8. doi: 10.1016/j.chiabu.2016.06.015

114. Cook JM, Riggs DS, Thompson R, Coyne JC, Sheikh JI. Posttraumatic stress disorder and current relationship functioning among World 
War II ex-prisoners of war. J Fam Psychol (2004) 18:36-45. doi: 10.1037/0893-3200.18.1.36

115. Elman I, Lowen S, Frederick BB, Chi W, Becerra L, Pitman RK. Functional neuroimaging of reward circuitry responsivity to monetary gains and losses in posttraumatic stress disorder. Biol Psychiatry (2009) 66:1083-90. doi: 10.1016/j.biopsych.2009.06.006

116. Sailer U, Robinson S, Fischmeister FP, Konig D, Oppenauer C, Lueger-Schuster B, et al. Altered reward processing in the nucleus accumbens and mesial prefrontal cortex of patients with posttraumatic stress disorder. Neuropsychologia (2008) 46:2836-44. doi: 10.1016/j. neuropsychologia.2008.05.022

117. Stein MB, Paulus MP. Imbalance of approach and avoidance: the yin and yang of anxiety disorders. Biol Psychiatry (2009) 66:1072-4. doi: 10.1016/j. biopsych.2009.09.023

118. Nawijn L, van Zuiden M, Frijling JL, Koch SB, Veltman DJ, Olff M. Reward functioning in PTSD: a systematic review exploring the mechanisms underlying anhedonia. Neurosci Biobehav Rev (2015) 51:189-204. doi: 10.1016/j.neubiorev.2015.01.019

119. Clausen AN, Youngren W, Sisante JF, Billinger SA, Taylor C, Aupperle RL, et al. and implicit behavioral tendencies for positive affective stimuli: a brief report. Front Psychol (2016) 7:758. doi: 10.3389/fpsyg.2016.00758

120. Galatzer-Levy IR, Bryant RA. 636,120 Ways to have posttraumatic stress disorder. Perspect Psychol Sci (2013) 8:651-62. doi: $10.1177 / 1745691613504115$

121. Lieberman L, Gorka SM, Funkhouser CJ, Shankman SA, Phan KL. Impact of posttraumatic stress symptom dimensions on psychophysiological reactivity to threat and reward. J Psychiatr Res (2017) 92:55-63. doi: 10.1016/j. jpsychires.2017.04.002

122. Felmingham KL, Falconer EM, Williams L, Kemp AH, Allen A, Peduto A, et al. Reduced amygdala and ventral striatal activity to happy faces in PTSD is associated with emotional numbing. PLoS One (2014) 9:e103653. doi: 10.1371/journal.pone.0103653

123. Frewen PA, Dozois DJA, Lanius RA. Assessment of anhedonia in psychological trauma: psychometric and neuroimaging perspectives. Eur J Psychotraumatol (2012) 3. doi: 10.3402/ejpt.v3i0.8587

124. DePierro JM, D'Andrea W, Frewen P. Anhedonia in trauma related disorders: the good, the bad, and the shut-down. In: Ritsner M. (Eds.) Anhedonia: A Comprehensive Handbook Volume II. Springer, Dordrecht (2014). doi: 10.1007/978-94-017-8610-2_7

125. Li M, D’Arcy C, Meng X. Maltreatment in childhood substantially increases the risk of adult depression and anxiety in prospective cohort studies: systematic review, meta-analysis, and proportional attributable fractions. Psychol Med (2015) 46:717-30. doi: 10.1017/S0033291715002743

126. Velikonja T, Fisher HL, Mason O, Johnson S. Childhood trauma and schizotypy: a systematic literature review. Psychol Med (2015) 45:947-63. doi: $10.1017 /$ S0033291714002086

127. Mayo D, Corey S, Kelly LH, Yohannes S, Youngquist AL, Stuart BK, et al. The role of trauma and stressful life events among individuals at clinical high risk for psychosis: a review. Front Psychiatry (2017) 8:55. doi: 10.3389/ fpsyt.2017.00055

128. Ford TC, Crewther DP. Factor analysis demonstrates a common schizoidal phenotype within autistic and schizotypal tendency: implications for neuroscientific studies. Front Psychiatry (2014) 5:117. doi: 10.3389/ fpsyt.2014.00117

129. Morrison KE, Pinkham AE, Penn DL, Kelsven S, Ludwig K, Sasson NJ. Distinct profiles of social skill in adults with autism spectrum disorder and schizophrenia. Autism Res (2017) 10:878-87. doi: 10.1002/aur.1734

130. Russell-Smith SN, Bayliss DM, Maybery MT. Unique sets of social and mood characteristics differentiate autistic and negative schizotypy traits in a young adult non-clinical sample. Pers Individ Dif (2013) 55:542-6. doi: 10.1016/j. paid.2013.04.030

131. Kanner L. Autistic disturbances of affective contact. Nervous Child (1943) 2:217-50.

132. Novacek DM, Gooding DC, Pflum MJ. Hedonic capacity in the broader autism phenotype: should social anhedonia be considered a characteristic feature? Front Psychol (2016) 7:666. doi: 10.3389/fpsyg.2016.00666
133. Rawlings D, Locarnini A. Dimensional schizotypy, autism, and unusual word associations in artists and scientists. J Res Pers (2008) 42:465-71. doi: 10.1016/j.jp. 2007.06.005

134. Russell-Smith SN, Maybery MT, Bayliss DM. Relationships between autisticlike and schizotypy traits: an analysis using the Autism Spectrum Quotient and Oxford-Liverpool Inventory of Feelings and Experiences. Pers Individ Dif (2011) 51:128-32. doi: 10.1016/j.paid.2011.03.027

135. Claridge G, McDonald A. An investigation into the relationships between convergent and divergent thinking, schizotypy, and autistic traits. Pers Individ Dif (2009) 46:794-9. doi: 10.1016/j.paid.2009.01.018

136. Barneveld PS, Pieterse J, de Sonneville L, van Rijn S, Lahuis B, van Engeland $\mathrm{H}$, et al. Overlap of autistic and schizotypal traits in adolescents with Autism Spectrum Disorders. Schizophr Res (2011) 126:231-6. doi: 10.1016/j. schres.2010.09.004

137. Dinsdale NL, Hurd PL, Wakabayashi A, Elliot M, Crespi BJ. How are autism and schizotypy related? Evidence from a non-clinical population. PLoS One (2013) 8:e63316. doi: 10.1371/journal.pone.0063316

138. Ford TC, Apputhurai P, Meyer D, Crewther DP. Confirmatory factor analysis of autism and schizophrenia spectrum traits. Pers Individ Dif (2017) 110:80-4. doi: 10.1016/j.paid.2017.01.033

139. Woodbury-Smith MR, Robinson J, Wheelwright S, Baron-Cohen S. Screening adults for Asperger Syndrome using the AQ: a preliminary study of its diagnostic validity in clinical practice. J Autism Dev Disord (2005) 35:331-5. doi: 10.1007/s10803-005-3300-7

140. Mason O, Claridge G. The Oxford-Liverpool Inventory of Feelings and Experiences (O-LIFE): further description and extended norms. Schizophr Res (2006) 82:203-11. doi: 10.1016/j.schres.2005.12.845

141. Chapman LJ, Chapman JP, Raulin ML. Scales for physical and social anhedonia. J Abnorm Psychol (1976) 85:374-82. doi: 10.1037/0021-843X.85.4.374

142. Berthoz S, Lalanne C, Crane L, Hill EL. Investigating emotional impairments in adults with autism spectrum disorders and the broader autism phenotype. Psychiatry Res (2013) 208:257-64. doi: 10.1016/j.psychres.2013.05.014

143. Chevallier C, Grezes J, Molesworth C, Berthoz S, Happe F. Brief report: selective social anhedonia in high functioning autism. J Autism Dev Disord (2012) 42:1504-9. doi: 10.1007/s10803-011-1364-0

144. Kazdin AE. Evaluation of the Pleasure Scale in the assessment of anhedonia in children. J Am Acad Child Adolesc Psychiatry (1989) 28:364-72. doi: 10.1097/00004583-198905000-00010

145. Gadow KD, Garman HD. Social anhedonia in children and adolescents with autism spectrum disorder and psychiatry referrals. J Clin Child Adolesc Psychol (2018) 53:1-12. doi: 10.1080/15374416.2018.1514611

146. Krach S, Paulus FM, Bodden M, Kircher T. The rewarding nature of social interactions. Front Behav Neurosci (2010) 4:22. doi: 10.3389/fnbeh.2010.00022

147. Delmonte S, Balsters JH, McGrath J, Fitzgerald J, Brennan S, Fagan AJ, et al. Social and monetary reward processing in autism spectrum disorders. Mol Autism (2012) 3:7. doi: 10.1186/2040-2392-3-7

148. Chevallier C, Kohls G, Troiani V, Brodkin ES, Schultz RT. The social motivation theory of autism. Trends Cogn Sci (2012) 16(4):231-9. doi: 10. 1016/j.tics.2012.02.007

149. Dubey I, Ropar D, Hamilton AF. Measuring the value of social engagement in adults with and without autism. Mol Autism (2015) 6:35. doi: 10.1186/ s13229-015-0031-2

150. Kohls G, Chevallier C, Troiani V, Schultz RT. Social 'wanting' dysfunction in autism: neurobiological underpinnings and treatment implications. J Neurodev Disord (2012) 4:10. doi: 10.1186/1866-1955-4-10

151. Mazurek MO. Loneliness, friendship, and well-being in adults with autism spectrum disorders. Autism (2014) 18:223-32. doi: 10.1177/1362361312474121

152. Berridge KC, Robinson TE, Aldridge JW. Dissecting components of reward: 'liking,' 'wanting', and learning. Curr Opin Pharmacol (2009) 9:65-73. doi: 10.1016/j.coph.2008.12.014

153. Hay DA, Martin NG, Foley D, Treloar SA, Kirk KM, Heath AC. Phenotypic and genetic analyses of a short measure of psychosis-proneness in a large-scale Australian twin study. Twin Res (2001) 4:30-40. doi: 10.1375/twin.4.1.30

154. MacDonald AW, 3rd, Pogue-Geile MF, Debski TT, Manuck S. Genetic and environmental influences on schizotypy: a community-based twin study. Schizophr Bull (2001) 27:47-58. doi: 10.1093/oxfordjournals.schbul.a006859 
155. Bader V, Tomppo L, Trossbach SV, Bradshaw NJ, Prikulis I, Leliveld SR, et al. Proteomic, genomic and translational approaches identify CRMP1 for a role in schizophrenia and its underlying traits. Hum Mol Genet (2012) 21:440618. doi: $10.1093 / \mathrm{hmg} / \mathrm{dds} 273$

156. Tomppo L, Hennah W, Miettunen J, Jarvelin MR, Veijola J, Ripatti S, et al. Association of variants in DISC1 with psychosis-related traits in a large population cohort. Arch Gen Psychiatry (2009) 66:134-41. doi: 10.1001/ archgenpsychiatry.2008.524

157. Feldman R. The neurobiology of human attachments. Trends Cogn Sci (2017) 21:80-99. doi: 10.1016/j.tics.2016.11.007

158. Docherty AR, Sponheim SR. Anhedonia as a phenotype for the Val158Met COMT polymorphism in relatives of patients with schizophrenia. J Abnorm Psychol (2008) 117:788-98. doi: 10.1037/a0013745

159. Eisenstein SA, Bogdan R, Chen L, Moerlein SM, Black KJ, Perlmutter JS, et al. Preliminary evidence that negative symptom severity relates to multilocus genetic profile for dopamine signaling capacity and D2 receptor binding in healthy controls and in schizophrenia. J Psychiatr Res (2017) 86:9-17. doi: 10.1016/j.jpsychires.2016.11.007

160. Loas G, Duru C, Godefroy O, Krystkowiak P. Hedonic deficits in Parkinson's disease: is consummatory anhedonia specific? Front Neurol (2014) 5:24. doi: 10.3389/fneur.2014.00024

161. Nagayama H, Maeda T, Uchiyama T, Hashimoto M, Nomoto N, Kano O, et al. Anhedonia and its correlation with clinical aspects in Parkinson's disease. J Neurol Sci (2017) 372:403-7. doi: 10.1016/j.jns.2016.10.051

162. Nummenmaa L, Tuominen L. Opioid system and human emotions. $\mathrm{Br} J$ Pharmacology (2017) 175(14):2737-49. doi: 10.1111/bph.13812

163. Bali A, Randhawa PK, Jaggi AS. Stress and opioids: role of opioids in modulating stress-related behavior and effect of stress on morphine conditioned place preference. Neurosci Biobehav Rev (2015) 51:138-50. doi: 10.1016/j.neubiorev.2014.12.018

164. Cinque C, Pondiki S, Oddi D, Di Certo MG, Marinelli S, Troisi A, et al. Modeling socially anhedonic syndromes: genetic and pharmacological manipulation of opioid neurotransmission in mice. Transl Psychiatry (2012) 2:e155. doi: 10.1038/tp.2012.83

165. Troisi A, Frazzetto G, Carola V, Di Lorenzo G, Coviello M, D’Amato FR, et al. Social hedonic capacity is associated with the A118G polymorphism of the mu-opioid receptor gene (OPRM1) in adult healthy volunteers and psychiatric patients. Soc Neurosci (2011) 6:88-97. doi: 10.1080/ 17470919.2010.482786

166. Resendez SL, Keyes PC, Day JJ, Hambro C, Austin CJ, Maina FK, et al. Dopamine and opioid systems interact within the nucleus accumbens to maintain monogamous pair bonds. Elife (2016) 5:e15325. doi: 10.7554/eLife.15325

167. Depue RA, Morrone-Strupinsky JV. A neurobehavioral model of affiliative bonding: implications for conceptualizing a human trait of affiliation. Behav Brain Sci (2005) 28:313-50. discussion 350-95. doi: 10.1017/S0140525X05000063

168. Lipina TV, Fletcher PJ, Lee FH, Wong AH, Roder JC. Disrupted-inschizophrenia-1 Gln31Leu polymorphism results in social anhedonia associated with monoaminergic imbalance and reduction of CREB and beta-arrestin-1,2 in the nucleus accumbens in a mouse model of depression. Neuropsychopharmacology (2013) 38:423-36. doi: 10.1038/ npp.2012.197

169. Walter H, Heckers S, Kassubek J, Erk S, Frasch K, Abler B. Further evidence for aberrant prefrontal salience coding in schizophrenia. Front Behav Neurosci (2010) 3:62. doi:10.3389/neuro.08.062.2009

170. Walter H, Kammerer H, Frasch K, Spitzer M, Abler B. Altered reward functions in patients on atypical antipsychotic medication in line with the revised dopamine hypothesis of schizophrenia. Psychopharmacology (2009) 206:121-32. doi: 10.1007/s00213-009-1586-4

171. Hooker CI, Benson TL, Gyurak A, Yin H, Tully LM, Lincoln SH. Neural activity to positive expressions predicts daily experience of schizophreniaspectrum symptoms in adults with high social anhedonia. J Abnorm Psychol (2014) 123:190-204. doi: 10.1037/a0035223

172. Gunther V, Lindner C, Dannlowski U, Kugel H, Suslow T. Amygdalar gray matter volume and social relating in schizophrenia. Neuropsychobiology (2016) 74:139-43. doi: 10.1159/000458528

173. Healey KL, Morgan J, Musselman SC, Olino TM, Forbes EE. Social anhedonia and medial prefrontal response to mutual liking in late adolescents. Brain Cogn (2014) 89:39-50. doi: 10.1016/j.bandc.2013.12.004
174. Yang XH, Wang Y, Wang DF, Tian K, Cheung EFC, Xie GR, et al. White matter microstructural abnormalities and their association with anticipatory anhedonia in depression. Psychiatry Res (2017) 264:29-34. doi: 10.1016/j. pscychresns.2017.04.005

175. Wang Y, Liu WH, Li Z, Wei XH, Jiang XQ, Geng FL, et al. Altered corticostriatal functional connectivity in individuals with high social anhedonia. Psychol Med (2016) 46:125-35. doi: 10.1017/S0033291715001592

176. Yin H, Tully LM, Lincoln SH, Hooker CI. Adults with high social anhedonia have altered neural connectivity with ventral lateral prefrontal cortex when processing positive social signals. Front Hum Neurosci (2015) 9:469. doi: 10.3389/fnhum.2015.00469

177. Wang Y, Deng Y, Fung G, Liu WH, Wei XH, Jiang XQ, et al. Distinct structural neural patterns of trait physical and social anhedonia: evidence from cortical thickness, subcortical volumes and inter-regional correlations. Psychiatry Res (2014) 224:184-91. doi: 10.1016/j.pscychresns. 2014.09.005

178. Enneking V, Krussel P, Zaremba D, Dohm K, Grotegerd D, Forster K, et al. Social anhedonia in major depressive disorder: a symptom-specific neuroimaging approach. Neuropsychopharmacology (2018) 44(5):883-9. doi: 10.1038/s41386-018-0283-6

179. Forbes EE. Where's the fun in that? Broadening the focus on reward function in depression. Biol Psychiatry (2009) 66:199-200. doi: 10.1016/j. biopsych.2009.05.001

180. Chein J, Albert D, O’Brien L, Uckert K, Steinberg L. Peers increase adolescent risk taking by enhancing activity in the brain's reward circuitry. Dev Sci (2011) 14:F1-10. doi: 10.1111/j.1467-7687.2010.01035.x

181. Albert D, Chein J, Steinberg L. Peer influences on adolescent decision making. Curr Dir Psychol Sci (2013) 22:114-20. doi: 10.1177/0963721412471347

182. Horton LE, Smith AA, Haas GL. The nature and timing of social deficits in child and adolescent offspring of parents with schizophrenia: preliminary evidence for precursors of negative symptoms? Schizophr Res (2014) 159:2730. doi: 10.1016/j.schres.2014.07.007

183. McGorry PD, Purcell R, Goldstone S, Amminger GP. Age of onset and timing of treatment for mental and substance use disorders: implications for preventive intervention strategies and models of care. Curr Opin Psychiatry (2011) 24:301-6. doi: 10.1097/YCO.0b013e3283477a09

184. McMakin DL, Olino TM, Porta G, Dietz LJ, Emslie G, Clarke G, et al. Anhedonia predicts poorer recovery among youth with selective serotonin reuptake inhibitor-treatment resistant depression. J Am Acad Child Adolesc Psychiatry (2012) 51:404-11. doi: 10.1016/j.jaac.2012.01.011

185. Meier A, Allen G. Romantic relationships from adolescence to young adulthood: evidence from the National Longitudinal Study of Adolescent Health. Sociol Q (2009) 50:308-35. doi: 10.1111/j.1533-8525.2009.01142.x

186. Selten J-P, van der Ven E, Rutten BPF, Cantor-Graae E. The social defeat hypothesis of schizophrenia: an update. Schizophr Bull (2013) 39:1180-6. doi: $10.1093 /$ schbul/sbt134

187. Allen NB, Badcock PBT. The social risk hypothesis of depressed mood: evolutionary, psychosocial, and neurobiological perspectives. Psychol Bull (2003) 129:887-913. doi: 10.1037/0033-2909.129.6.887

188. Rohde P. The relevance of hierarchies, territories, defeat for depression in humans: hypotheses and clinical predictions. J Affect Disord (2001) 65:22130. doi: 10.1016/S0165-0327(00)00219-6

189. Gilbert P, Allan S, Brough S, Melley S, Miles JN. Relationship of anhedonia and anxiety to social rank, defeat and entrapment. J Affect Disord (2002) 71:141-51. doi: 10.1016/S0165-0327(01)00392-5

190. Ethridge P, Kujawa A, Dirks MA, Arfer KB, Kessel EM, Klein DN, et al. Neural responses to social and monetary reward in early adolescence and emerging adulthood. Psychophysiology (2017) 54(12):1786-99. doi: 10.1111/ psyp. 12957

191. Casey BJ, Jones RM, Somerville LH. Braking and accelerating of the adolescent brain. J Res Adolesc (2011) 21:21-33. doi: 10.1111/j.1532-7795.2010.00712.x

192. Corral-Frias NS, Nikolova YS, Michalski LJ, Baranger DA, Hariri AR, Bogdan R. Stress-related anhedonia is associated with ventral striatum reactivity to reward and transdiagnostic psychiatric symptomatology. Psychol Med (2015) 45:2605-17. doi: 10.1017/S0033291715000525

193. Kohls G, Peltzer J, Herpertz-Dahlmann B, Konrad K. Differential effects of social and non-social reward on response inhibition in children and adolescents. Dev Sci (2009) 12. doi: 10.1111/j.1467-7687.2009.00816.x 
194. Kujawa A, Kessel EM, Carroll A, Arfer KB, Klein DN. Social processing in early adolescence: associations between neurophysiological, self-report, and behavioral measures. Biol Psychol (2017) 128:55-62. doi: 10.1016/j. biopsycho.2017.07.001

195. Fonseca-Pedrero E, Gooding DC, Ortuno-Sierra J, Pflum M, Paino M, Muniz J. Classifying risk status of non-clinical adolescents using psychometric indicators for psychosis spectrum disorders. Psychiatry Res (2016) 243:24654. doi: 10.1016/j.psychres.2016.06.049

196. Bodapati AS, Jenkins LM, Sharma RP, Rosen C. Visual memory uniquely predicts anhedonia in schizophrenia but not bipolar disorder. J Neuropsychol (2017) 13(1):136-46. doi: 10.1111/jnp.12124

197. Gooding DC, Padrutt ER, Pflum MJ. The predictive value of the NEOFFI items: parsing the nature of social anhedonia using the Revised Social Anhedonia Scale and the ACIPS. Front Psychol (2017) 8:147. doi: 10.3389/ fpsyg.2017.00147

198. Li LY, Karcher NR, Kerns JG, Fung CK, Martin EA. The subjective-objective deficit paradox in schizotypy extends to emotion regulation and awareness. J Psychiatr Res (2019) 111:160-8. doi: 10.1016/j.jpsychires.2019.01.026

199. Yang Y, Yang ZY, Zou YM, Shi HS, Wang Y, Xie DJ, et al. Low-pleasure beliefs in patients with schizophrenia and individuals with social anhedonia. Schizophr Res (2018) 201:137-44. doi: 10.1016/j.schres.2018.05.018

200. Hu HX, Chu MY, Yang Y, Wang LL, Zhang RT, Lui SSY, et al. Mediation effect of beliefs about pleasure and emotional experience between social anhedonia and prediction of pleasant events. Psychiatry Res (2018) 264:3945. doi: 10.1016/j.psychres.2018.03.070

201. Langvik E, Borgen Austad S. Psychometric properties of the SnaithHamilton Pleasure Scale and a facet-level analysis of the relationship between anhedonia and extraversion in a nonclinical sample. Psychol Rep (2019) 122:360-75. doi: 10.1177/0033294118756336

202. Strauss GP, Nuñez A, Ahmed AO, Barchard KA, Granholm E, Kirkpatrick $\mathrm{B}$, et al. The latent structure of negative symptoms in schizophrenia. JAMA Psychiatry (2018) 75:1271-9. doi: 10.1001/jamapsychiatry.2018.2475

203. Christensen AP, Gross GM, Golino HF, Silvia PJ, Kwapil TR. Exploratory graph analysis of the multidimensional schizotypy scale. Schizophr Res (2018). doi: 10.1016/j.schres.2018.12.018
204. Cihan B, Saka MC, Gonullu I, Ozel Kizil ET, Baskak B, Atbasoglu EC. Exploring the role of social anhedonia in the positive and negative dimensions of schizotypy in a non-clinical sample. Noropsikiyatri Ars (2015) 52:272-8. doi: 10.5152/npa.2015.7473

205. Smith EA, Bolinskey PK, Guidi JP, Myers KR, Schuder KM, James AV, et al. Further examination of the factor structure of the Chapman Psychosis Proneness Scales (CPPS). Psychiatry Res (2016) 238:257-63. doi: 10.1016/j. psychres.2016.02.057

206. Cacioppo JT, Cacioppo S, Capitanio JP, Cole SW. The neuroendocrinology of social isolation. Annu Rev Psychol (2014) 66:733-67. doi: 10.1146/ annurev-psych-010814-015240

207. Bjork JM, Knutson B, Fong GW, Caggiano DM, Bennett SM, Hommer DW. Incentive-elicited brain activation in adolescents: similarities and differences from young adults. J Neurosci (2004) 24:1793-802. doi: 10.1523/ JNEUROSCI.4862-03.2004

208. Bjork JM, Smith AR, Chen G, Hommer DW. Adolescents, adults and rewards: comparing motivational neurocircuitry recruitment using fMRI. PLoS One (2010) 5:e11440. doi: 10.1371/journal.pone.0011440

209. Walker DM, Bell MR, Flores C, Gulley JM, Willing J, Paul MJ. Adolescence and reward: making sense of neural and behavioral changes amid the chaos. J Neurosci (2017) 37:10855-66. doi: 10.1523/JNEUROSCI.1834-17.2017

210. Cacioppo JT, Cacioppo S. Social relationships and health: the toxic effects of perceived social isolation. Soc Personal Psychol Compass (2014) 8:58-72. doi: $10.1111 /$ spc3.12087

Conflict of Interest Statement: The authors declare that the research was conducted in the absence of any commercial or financial relationships that could be construed as a potential conflict of interest.

Copyright (C) 2019 Barkus and Badcock. This is an open-access article distributed under the terms of the Creative Commons Attribution License (CC BY). The use, distribution or reproduction in other forums is permitted, provided the original author(s) and the copyright owner(s) are credited and that the original publication in this journal is cited, in accordance with accepted academic practice. No use, distribution or reproduction is permitted which does not comply with these terms. 